Check for updates

Cite this: RSC Adv., 2019, 9, 23994

Received 11th February 2019

Accepted 27th June 2019

DOI: 10.1039/c9ra01073d

rsc.li/rsc-advances

\section{Synergistic toughening of polypropylene with ultra-high molecular weight polyethylene and elastomer-olefin block copolymers $\uparrow$}

\author{
Lucheng Qi, ${ }^{a}$ Lei Wu, ${ }^{+}{ }^{a}$ Ren He, ${ }^{c}$ Hui Cheng, ${ }^{a}$ Boping Liu ${ }^{b}$ and Xuelian He (D) *a
}

Blends of polypropylene (PP) and ultra-high molecular weight polyethylene (UHMWPE) with elastomerolefin block copolymers $(\mathrm{OBC})$ were prepared using an ultrasonic twin-screw extruder, and the mechanical, thermal, and rheological properties of the blends were investigated. The interfacial interactions among PP, OBC, and UHMWPE showed that the PP/OBC/UHMWPE blends formed a coreshell structure with UHMWPE as the core and $O B C$ as the shell. The crystallization temperature and the crystallinity of the blends were improved for the heterogeneous nucleation between PP- and OBCcovered UHMWPE particles. Moreover, the mechanical and thermal properties of PP/UHMWPE blends have also been greatly improved by adding OBC. Furthermore, it was evident that the OBC-covered HHMWPE particles became smaller under the application of ultrasonic irradiation, so the interfacial interactions between the particles and the PP matrix were enhanced and the impact strength of the blends was improved.

\section{Introduction}

As one of the most widely used thermoplastic plastics in the world, polypropylene (PP) has been used more and more widely in all walks of life. Research studies on high toughness polypropylene blends have great scientific significance. ${ }^{\mathbf{1 - 6}}$ Plastic toughening polypropylene is a common method, which mainly uses high toughness polymers (HDPE, UHMWPE, etc.) to blend with low toughness polypropylene to prepare blends, in order to improve the impact resistance of polypropylene. However, due to the thermal incompatibility between polypropylene and toughened plastics, the properties of the blends are often unsatisfactory. $^{7}$

Melt blending is one of the most common methods for processing polymer materials. When the two materials are dispersed unevenly due to the difference of viscosity, the screw speed is often increased to improve the dispersion. ${ }^{8}$ But for some polymers such as PP, if the screw speed is too high and the shear force is too large, the material will degrade and the

${ }^{a}$ Shanghai Key Laboratory of Multiphase Material Chemical Engineering, East China University of Science and Technology, Shanghai 200237, China. E-mail: hexl@ecust. edu.cn; lcqi_1224@foxmail.com; edwood_vip@163.com; huihyva@ecust.edu.cn; Tel: +86-21-64253364

${ }^{b}$ College of Materials and Energy, South China Agricultural University, Guangzhou 510642, China. E-mail: boping@scau.edu.cn

'Daqing Petrochemical Research Center of PetroChina, Daqing 163714, China. E-mail: renhe459@petrochina.com.cn

$\dagger$ Electronic supplementary information (ESI) available. See DOI: 10.1039/c9ra01073d

\$ Co-first author: Lei Wu mechanical properties will decline. The application of ultrasound in a screw extruder can solve this problem very well. The cavitation of ultrasound can produce huge energy, making the polymer disperse evenly, and the action time is short, so it will not cause serious degradation of polymer molecular chains. ${ }^{9}$ Feng et al. ${ }^{10}$ installed an ultrasonic device at the head of twinscrew extruder and blended melting PP and EPDM, and obviously improved the toughness of the blends. Isayev et al. ${ }^{\mathbf{1 1}}$ found that carbon nanotubes dispersed well in polyetherimide (PEI) with multi-walled carbon nanotube (MWNT) content of $10 \mathrm{wt} \%$ when melt extruding PEI and MWNTs using ultrasonic screw extruder. Chen et al. ${ }^{12}$ studied the effect of different ultrasonic power on the properties of PP/EPDM blends and found that with the increase of ultrasonic power, the particle size of rubber phase decreased gradually.

Since the random copolymer ethylene-octene copolymer (POE) of thermoplastic elastomer ethylene-octene was developed by Dow Chemistry in the United States, polypropylene toughened using thermoplastic elastomers has gradually replaced the traditional rubber toughened polypropylene. ${ }^{\mathbf{1 3 , 1 4}}$ POE is a thermoplastic elastomer with a relatively narrow molecular weight distribution and uniform short branched chain distribution synthesized with metallocene as a catalyst. Compared with rubber toughened PP, POE toughened PP has better processability, and its weatherability and low temperature impact resistance are improved. ${ }^{15}$ As a new generation of elastomer, ethylene-octene block copolymer (OBC) has better mechanical and thermal properties than traditional elastomers such as POE. ${ }^{\mathbf{1 6}}$ The special block molecular structure of OBC gives it properties that many other elastomers do not possess. 
Compared with other elastomers (POE, Styrene-ethylenebutylene-stryrene, etc.), OBC has better impact resistance, better compression deformation resistance and higher heat resistance temperature. ${ }^{17}$ Pardo et al. ${ }^{18}$ toughened PP/OBC blends with ash and they found that the fracture absorption energy of the blends increased with the increase of ash content, indicating that the toughness of the blends was enhanced. Liu et al. ${ }^{19}$ studied the effect of $\mathrm{OBC}$ with different octene content on toughening PP. The results showed that when the octene content in soft segment of OBC was higher, the toughening effect of OBC on PP was better. Li et al. ${ }^{20}$ prepared $\mathrm{PP} / \mathrm{OBC}$ nanofibers with $\mathrm{OBC}$ as matrix and $\mathrm{PP}$ as disperse fibers. The results showed that the nanofibers had excellent mechanical properties. He et al. added OBC in PP/HDPE blends and significantly improved the impact resistance of $\mathrm{PP} / \mathrm{HDPE}$ blends. $^{21}$

UHMWPE is a thermoplastic with excellent properties, the molecular weight of which is over 1.5 million. Compared with HDPE, UHMWPE has fewer branched chains and higher molecular weight. UHMWPE has almost all the advantages of engineering plastics such as excellent rigidity and toughness, wear resistance, corrosion resistance, self-lubrication, non-toxic and can be used as environmental protection materials. Improving the mechanical properties of PP by UHMWPE has been a research hotspot in the scientific circles. Liu et al. ${ }^{22}$ found that adding PP was more helpful to improve the fluidity of UHMWPE than adding HDPE. PP mainly concentrated on the surface of the blend and contacted the barrel of the extruder, increased the friction between the blend and the inner wall of the barrel, and improved the forward conveying ability of the material. ${ }^{23}$ However, on the one hand, because the molecular chains of UHMWPE are closely intertwined, so its processing is difficult resulting from the high viscosity and poor fluidity; on the other hand, because the compatibility between UHMWPE and PP is poor, purpose of improving the mechanical properties of PP by blending is not achieved. Using compatibilizers to blend with PP and UHMWPE can not only overcome the shortcomings of UHMWPE processing difficulties, but also improve the interfacial compatibility of UHMWPE and PP, making it possible for UHMWPE to strengthen and toughen PP.

In the present work, UHMWPE was used to strengthen and toughen PP, and elastomer OBC as the compatibilizers. The mechanical, thermal and rheological properties of $\mathrm{PP} / \mathrm{OBC} /$ UHMWPE blends were studied by adding UHMWPE and OBC. The effect of the cross-section of the blend was observed and analyzed. Finally, the dispersion of UHMWPE in the blend was further improved by ultrasonic wave, and the mechanical properties of the blend were improved.

\section{Experiment}

\subsection{Materials}

Polypropylene (PP, PPH-T03) with the melt flow rate (MFR) of $3.6 \mathrm{~g} / 10 \mathrm{~min}\left(230^{\circ} \mathrm{C}, 2.16 \mathrm{~kg}\right)$ and the weight-average molecular weight $\left(M_{\mathrm{w}}\right)$ of $4.1 \times 10^{2} \mathrm{~kg} \mathrm{~mol}^{-1}$ was purchased from Sinopec Zhenhai Refining and Chemical Company Ltd. (Ningbo, Zhejiang, China). Olefin block copolymers (OBC, 9100, $12 \mathrm{~mol} \%$ octene) with MFR of $1 \mathrm{~g} / 10 \mathrm{~min}\left(190{ }^{\circ} \mathrm{C}, 2.16 \mathrm{~kg}\right), M_{\mathrm{w}}$ of $160 \mathrm{~kg}$ $\mathrm{mol}^{-1}$, and the polymer dispersity index (PDI) of 2.4 were purchased from the Dow Chemical Company. Ultra-high molecular weight polyethylene (UHMWPE, $0.943 \mathrm{~g} \mathrm{~cm}^{-3}$ ) with the weight-average molecular weight $\left(M_{\mathrm{w}}\right)$ of $1.5 \times 10^{3} \mathrm{~kg} \mathrm{~mol}^{-1}$ was purchased from Sinopec Qilu Petrochemical Branch Company Ltd. (Zibo, Shandong, China). The antioxidant Irganox 1010 (pentaerythritol tetrakis-3-(3,5-di-tert-butyl-4hydroxyphenyl)propionate) was purchased from the BASF (Ludwigshafen, Germany).

\subsection{Preparation of blends}

PP, UHMWPE and OBC were vacuum dried at $75{ }^{\circ} \mathrm{C}$ for 4 hours to remove the adsorbed moisture. Then they were premixed according to a certain mass ratio (Table 1 ), followed by adding $0.2 \mathrm{wt} \%$ Irganox 1010. After homogeneous mixing, they were extruded and granulated by an ultrasonic twin-screw extruder (see Fig. S. $1 \dagger$ ). The SHJ-20 co-rotating intermeshing twin-screw extruder with the screw diameter of $21.7 \mathrm{~mm}$ and the length to diameter ratio of 40 was produced by the Nanjing Jieya Company. The extruder was divided into eight segments and each segment was composed of a separated heating and watercooling system. The temperature of the first to the seventh segments of the extruder is $170{ }^{\circ} \mathrm{C}, 180{ }^{\circ} \mathrm{C}, 190{ }^{\circ} \mathrm{C}, 200{ }^{\circ} \mathrm{C}$, $200{ }^{\circ} \mathrm{C}, 195{ }^{\circ} \mathrm{C}, 190{ }^{\circ} \mathrm{C}$, the temperature of the head is $190{ }^{\circ} \mathrm{C}$, the feed rate was maintained at $10 \mathrm{rpm}$ with the screw speed of $200 \mathrm{rpm}$ and the flow rate of the die of about $7.4 \mathrm{~g} \mathrm{~min}^{-1}$. We installed two ultrasonic launchers produced by the Shanghai Shengxi Instrument Company (China) at the head of the extruder with the frequency of $20 \mathrm{kHz}$ and a power range of 0 to $600 \mathrm{~W}$. The diameter of the ultrasonic horn tips was $16 \mathrm{~mm}$, and the gap in the ultrasonic region was $8 \mathrm{~mm}$ with the width of $13 \mathrm{~mm}$ in the elliptical channel.

After drying, the performance was tested.

\subsection{Mechanical properties}

Tensile test was carried out according to the GB/T16421-1996 test method using an Instron 3367 test machine with a cross-

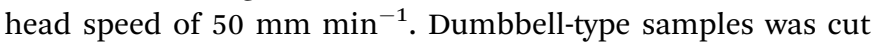

Table 1 Preparation parameters for PP/OBC/UHMWPE blends ${ }^{a}$

Ultrasonic power

Sample PP (g) OBC (g) UHMWPE (g) (W)

PP

$\mathrm{P} / \mathrm{U}(99 / 1)$

$\mathrm{P} / \mathrm{O} / \mathrm{U}(99 / 3 / 1)$

$\mathrm{P} / \mathrm{O} / \mathrm{U}(99 / 6 / 1)$

$\mathrm{P} / \mathrm{O}(99 / 6)$

$\mathrm{P} / \mathrm{O} / \mathrm{U}(99 / 6 / 0.5)$

$\mathrm{P} / \mathrm{O} / \mathrm{U}(99 / 6 / 1.5)$

$\mathrm{P} / \mathrm{O} / \mathrm{U}(99 / 6 / 2.0)$

$\mathrm{P} / \mathrm{O} / \mathrm{U}(99 / 6 / 1.5)-200$

$\mathrm{P} / \mathrm{O} / \mathrm{U}(99 / 6 / 1.5)-400$

$\mathrm{P} / \mathrm{O} / \mathrm{U}(99 / 6 / 1.5)-600$

$\begin{array}{rrrr}100 & - & - & - \\ 99 & - & 1 & - \\ 99 & 3 & 1 & - \\ 99 & 6 & 1 & - \\ 99 & 6 & - & - \\ 99 & 6 & 0.5 & - \\ 99 & 6 & 1.5 & - \\ 99 & 6 & 2.0 & - \\ 99 & 6 & 1.5 & 200 \\ 99 & 6 & 1.5 & 400 \\ 99 & 6 & 1.5 & 600\end{array}$

${ }^{a}$ The ultrasonic power is the power of one launcher. 


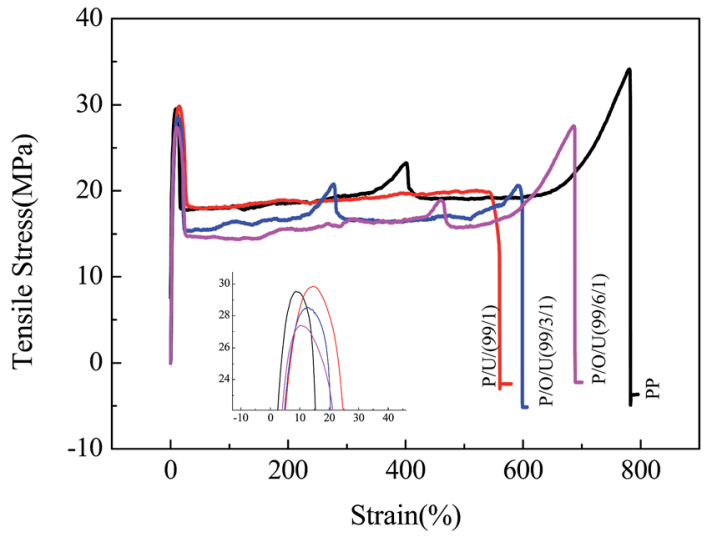

Fig. 1 The tensile stress-strain curves of PP/OBC/UHMWPE blends with different $\mathrm{OBC}$ contents.

with a thickness of $2 \mathrm{~mm}$ and length of $20 \mathrm{~mm}$ from the tablet samples for the tensile test. The tablet samples were pressed in a tableting machine (Model GT-7014-P, GOTECH Instrument Company, Taiwan) through the following process. Firstly, dried pellets were placed in the mold and preheated for $5 \mathrm{~min}$ at $200^{\circ} \mathrm{C}$, and the samples were pressed at $8 \mathrm{MPa}$ for $5 \mathrm{~min}$ after 15 exhaust circulations at $5 \mathrm{MPa}$. Then the tablet samples were cooled by water circulation for 3 min.

The impact strength of injection-molded samples was measured according to the GB/T1843-2008 test method using an Izod impact test machine (Model 9050, CEAST Company, Pianezza, Italy). Injection-molded samples were prepared in a micro-injection molding machine (Model Minijet, HAAKE Instrument Company, Germany) through the following process. The dried pellets were placed in a cylinder and preheated for $5 \mathrm{~min}$ at $200^{\circ} \mathrm{C}$. Then samples were injected into the mold and maintained at $90{ }^{\circ} \mathrm{C}$ with the injection pressure of 1000 bar and the pressure keeping time of $20 \mathrm{~s}$. We obtained an impact spline with a thickness of $4 \mathrm{~mm}$, width of $10 \mathrm{~mm}$, and notch-bottom radius of $0.25 \mathrm{~mm}$ after cooling the mold at room temperature.

\subsection{Thermal measurements}

Differential scanning calorimeter (Model DSC Q200, TA Instrument Company, New Castle, DE, USA) was used to test the thermal performance of the prepared samples. Firstly, $5 \mathrm{mg}$ samples were placed in the testing chamber and raised the



Fig. 2 The tensile stress-strain curves of PP/OBC/UHMWPE blends with different UHMWPE contents.

temperature to $200{ }^{\circ} \mathrm{C}$ at $10{ }^{\circ} \mathrm{C} \mathrm{min}^{-1}$. The temperature of the test chamber was kept at $200{ }^{\circ} \mathrm{C}$ for $5 \mathrm{~min}$ to eliminate the thermal history. Then the temperature was decreased from $200{ }^{\circ} \mathrm{C}$ to $40{ }^{\circ} \mathrm{C}$ at $10{ }^{\circ} \mathrm{C} \min ^{-1}$ and the crystallization curves were recorded. Next the temperature was raised to $200{ }^{\circ} \mathrm{C}$ at $10{ }^{\circ} \mathrm{C} \mathrm{min}{ }^{-1}$ and the melting curves were recorded. The whole process was performed under a nitrogen atmosphere with a flow rate of $50 \mathrm{~mL} \mathrm{~min}{ }^{-1}$.

The formula for calculating the crystallinity of samples is as follows:

$$
X_{\mathrm{c}}=\frac{\Delta H_{\mathrm{m}}}{\Delta H_{\mathrm{c}}} \times 100 \%
$$

where $\Delta H_{\mathrm{m}}$ represents the melting enthalpy $\left(\mathrm{J} \mathrm{g}^{-1}\right)$ of the sample, $\Delta H_{\mathrm{c}}$ represents the melting enthalpy of $100 \%$ crystalline PP or PE; $\Delta H_{\mathrm{c}}$ PP is $209.2 \mathrm{~J} \mathrm{~g}^{-1}$ (ref. 24) and $\Delta H_{\mathrm{c}} \mathrm{PE}$ is $290 \mathrm{~J}$ $\mathrm{g}^{-1} \cdot{ }^{25}$

\subsection{Morphological characterization}

The morphologies of the prepared samples were characterized using a field emission scanning electron microscope (FE-SEM) produced by the FEI Company (Model NOVA Nano SEM450, Hillsboro, OR, USA). The tablet samples were first fractured in liquid nitrogen, and then the fractured cross-section was etched with $n$-heptane for 5 hours and covered with platinum.

Table 2 Mechanical properties of PP/OBC/UHMWPE blends

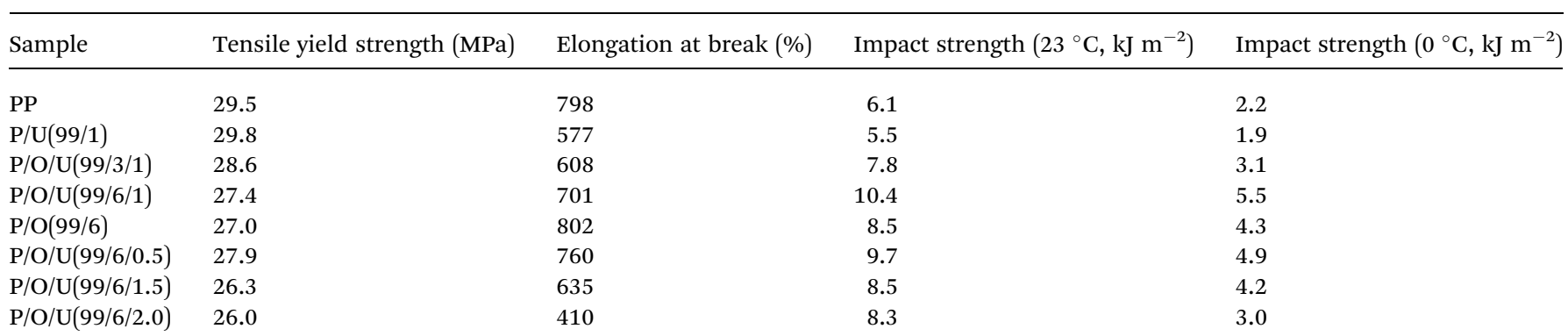




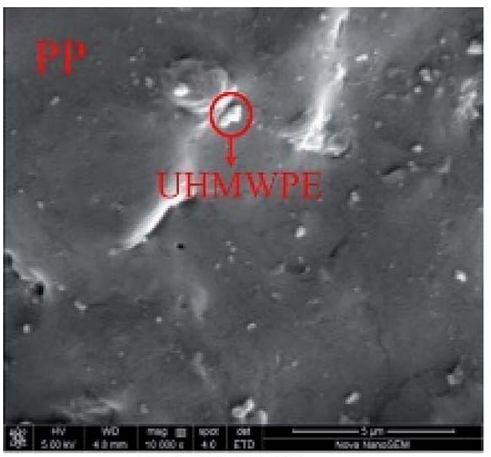

P/U(99/1)



$\mathrm{P} / \mathrm{O} / \mathrm{U}(99 / 6 / 0.5)$

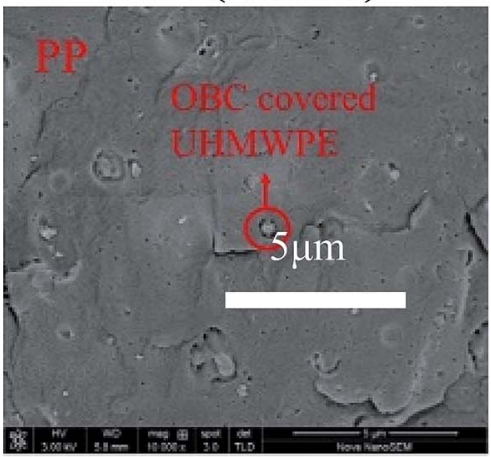

$\mathrm{P} / \mathrm{O} / \mathrm{U}(99 / 6 / 1.5)-200$

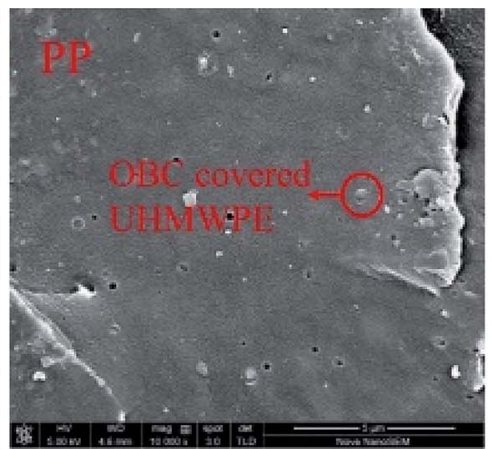

$\mathrm{P} / \mathrm{O} / \mathrm{U}(99 / 6 / 1)$

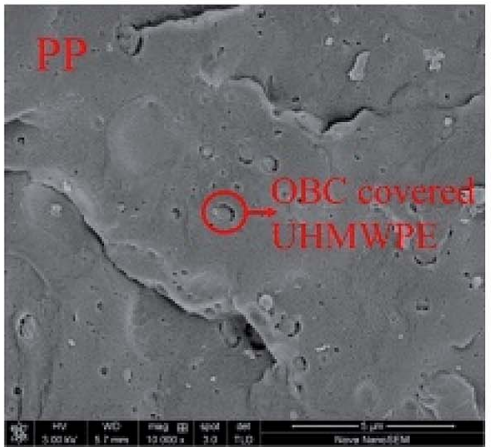

$\mathrm{P} / \mathrm{O} / \mathrm{U}(99 / 6 / 1.5)$

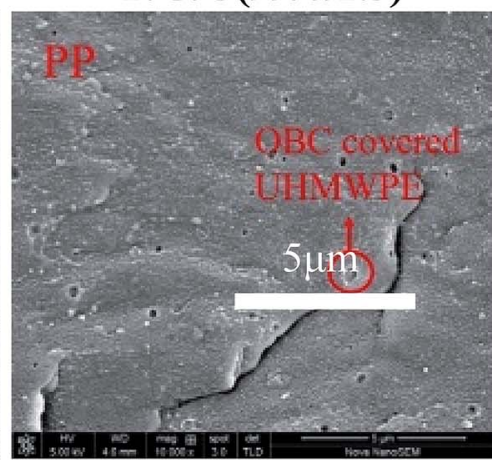

$\mathrm{P} / \mathrm{O} / \mathrm{U}(99 / 6 / 1.5)-400$

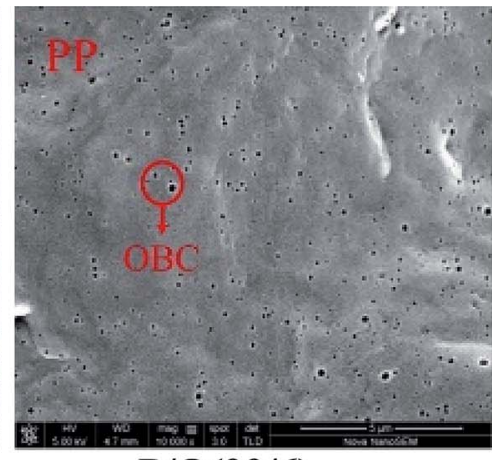

P/O(99/6)

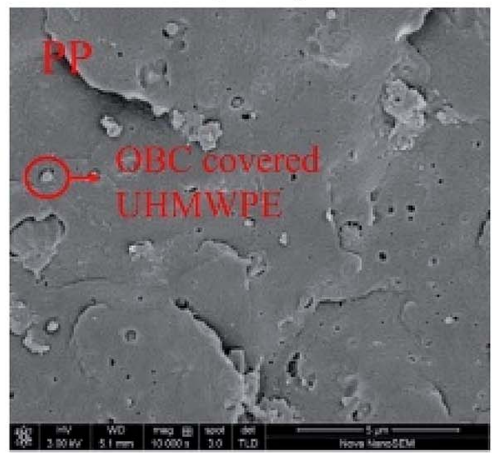

$\mathrm{P} / \mathrm{O} / \mathrm{U}(99 / 6 / 2)$

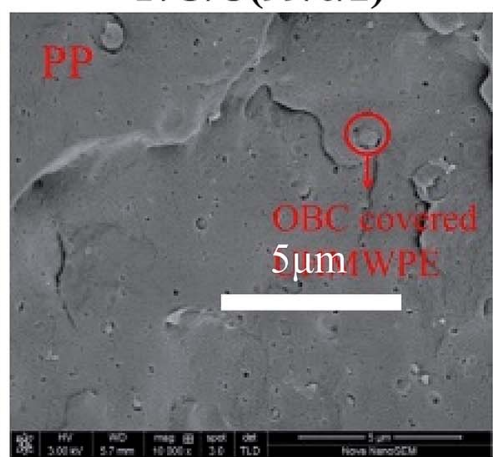

Fig. 3 SEM images for fracture surfaces of PP/OBC/UHMWPE blends.

\subsection{Rheological analysis}

The dynamic rheological properties of the samples were studied using the parallel-plate-mode of the TA ARES rheometer. The samples were tested with a thickness of $2 \mathrm{~mm}$ and diameter of $25 \mathrm{~mm}$ at $200{ }^{\circ} \mathrm{C}$. We applied the fixed strain amplitude of $2 \%$ and the frequency range of 0.1 to $100 \mathrm{rad} \mathrm{s}^{-1}$.

\subsection{Contact angle measurement}

The static contact angle of the substrate were measured using the sessile drop method of the contact angle meter (Model OCA20, Datatphysics Company, Stuttgart, Germany) relative to water and diiodomethane $(3 \mu \mathrm{L})$. Surface energy, interfacial tension and adhesive energy were calculated by the Wu's equations (eqn (1)-(5)), where $\theta$ is the contact angle, $\gamma$ is the surface energy $\left(\mathrm{mN} \mathrm{m}^{-1}\right), \gamma^{\mathrm{p}}$ and $\gamma^{\mathrm{d}}$ are the polar component and the dispersion component of surface energy respectively, indices 1 and 2 denote different materials, $\gamma_{12}$ is the interfacial tension $\left(\mathrm{mN} \mathrm{m}^{-1}\right)$ between two phases, and $W_{12}$ is the adhesive energy of two phases $\left(\mathrm{mN} \mathrm{m}^{-1}\right)$.

$$
\begin{gathered}
\left(1+\cos \theta_{\mathrm{H}_{2} \mathrm{O}}\right) \gamma_{\mathrm{H}_{2} \mathrm{O}}=4\left(\frac{\gamma_{\mathrm{H}_{2} \mathrm{O}}^{\mathrm{d}} \gamma^{\mathrm{d}}}{\gamma_{\mathrm{H}_{2} \mathrm{O}}^{\mathrm{d}}+\gamma^{\mathrm{d}}}+\frac{\gamma_{\mathrm{H}_{2} \mathrm{O}}^{\mathrm{p}} \gamma^{\mathrm{p}}}{\gamma_{\mathrm{H}_{2} \mathrm{O}}^{\mathrm{p}}+\gamma^{\mathrm{p}}}\right) \\
\left(1+\cos \theta_{\mathrm{CH}_{2} \mathrm{I}_{2}}\right) \gamma_{\mathrm{CH}_{2} \mathrm{I}_{2}}=4\left(\frac{\gamma_{\mathrm{CH}_{2} \mathrm{I}_{2}}^{\mathrm{d}} \gamma^{\mathrm{d}}}{\gamma_{\mathrm{CH}_{2} \mathrm{I}_{2}}^{\mathrm{d}}+\gamma^{\mathrm{d}}}+\frac{\gamma_{\mathrm{CH}_{2} \mathrm{I}_{2}}^{\mathrm{p}} \gamma^{\mathrm{p}}}{\gamma_{\mathrm{CH}_{2} \mathrm{I}_{2}}^{\mathrm{p}}+\gamma^{\mathrm{p}}}\right) \\
\gamma=\gamma^{\mathrm{d}}+\gamma^{\mathrm{p}} \\
\gamma_{12}=\gamma_{1}+\gamma_{2}-4\left(\frac{\gamma_{1}^{\mathrm{d}} \gamma_{2}^{\mathrm{d}}}{\gamma_{1}^{\mathrm{d}}+\gamma_{2}^{\mathrm{d}}}+\frac{\gamma_{1}^{\mathrm{p}} \gamma_{2}^{\mathrm{p}}}{\gamma_{1}^{\mathrm{p}}+\gamma_{2}^{\mathrm{p}}}\right) \\
W_{12}=2\left(\gamma_{1}^{\mathrm{d}} \gamma_{2}^{\mathrm{d}}\right)^{1 / 2}+2\left(\gamma_{1}^{\mathrm{p}} \gamma_{2}^{\mathrm{p}}\right)^{1 / 2}
\end{gathered}
$$




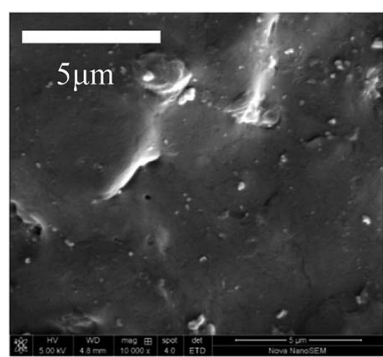

P/U(99/1)-10000X

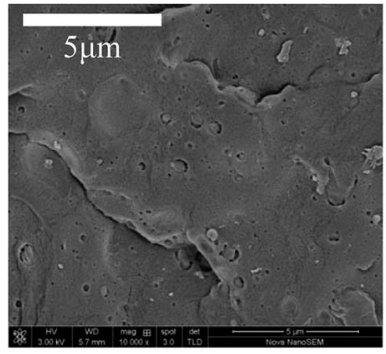

$\mathrm{P} / \mathrm{O} / \mathrm{U}(99 / 6 / 1.5)-10000 \times$

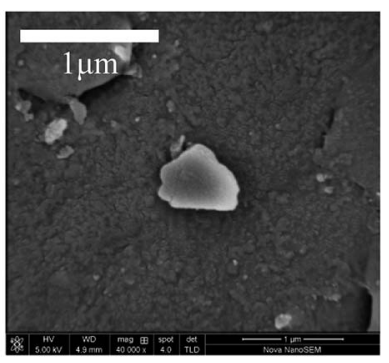

$\mathrm{P} / \mathrm{U}(99 / 1)-40000 \times$

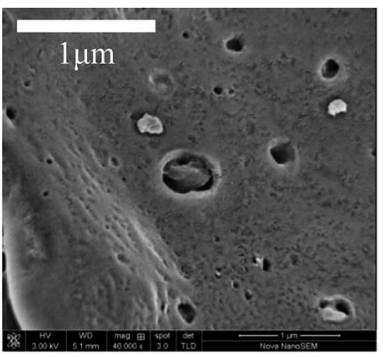

$\mathrm{P} / \mathrm{O} / \mathrm{U}(99 / 6 / 1.5)-40000 \times$
Fig. 4 SEM images of PP/OBC/UHMWPE blends with different magnifications.

\section{Results and discussion}

\subsection{Mechanical properties of the blends}

The effect of OBC content on the tensile stress-strain curve of the blends was shown in Fig. 1. It can be seen that the elongation at break and the absorption energy at break of PP/ UHMWPE blends decreased obviously compared with PP. The notch impact strength data of PP/UHMWPE blends showed that the impact strength of PP/UHMWPE blends was not improved but decreased because of the poor compatibility between PP and UHMWPE. So simple blending can't toughen PP.

Fig. 2 and Table 2 showed that with the increase of the content of OBC, the notched impact strength of PP/OBC/ UHMWPE blends increased significantly, while the tensile yield strength decreased slightly. When the content of OBC was $6 \mathrm{wt} \%$, the impact strength of the blends reached $10.4 \mathrm{~kJ}$ $\mathrm{m}^{-2}$ and the tensile yield strength is $27.4 \mathrm{MPa}$. Compared with pure $\mathrm{PP}$, the impact strength increased by $70 \%$ and the tensile strength decreased only by $7 \%$. On the other hand, with the increase of UHMWPE content, the tensile yield strength and impact strength of PP/OBC/UHMWPE blends increased first and then decreased. When the UHMWPE content was $1 \%$, the mechanical properties of the blends were the best. And when the UHMWPE content exceeded $1 \mathrm{wt} \%$, the impact strength and tensile yield strength of the blends began to decrease gradually. The reason was that UHMWPE, unlike HDPE, has excellent tensile properties. When a small amount of UHMWPE was added to PP/OBC blends, it can be strengthened and toughened at the same time. When the amount of UHMWPE was high, it is difficult to disperse homogeneously in the blends due to its high viscosity when blending with PP and OBC. The mechanical properties of the blends decreased gradually due to the mechanical defects of the blends.

At the same time, when the addition of UHMWPE was less than $1.0 \mathrm{wt} \%$, the notched impact strength of blends at low temperature increased gradually with the addition of UHMWPE, showing excellent impact resistance at low temperature.

Usually, PP and PE are semi-crystalline polymers, which have two parts: crystalline and amorphous regions. The molecular chains in crystalline regions are arranged regularly, and chain winding and slipping are not easy to occur. The molecular chains in noncrystalline regions are relatively free. They can form ring molecules, tethered molecules, entangled chains and other structures. The chain morphology of crystalline region has an important influence on the mechanical properties of materials. Generally speaking, the tighter the entanglement is, the more the lacing molecules are, the better the mechanical properties of materials, such as UHMWPE, which has a very long polymer chain and there are many random entanglement chains formed in the amorphous region of UHMWPE. Unwrapping requires a lot of energy, so UHMWPE has excellent mechanical properties. When UHMWPE is added to PP, due to their poor compatibility, the molecular chains of PP and UHMWPE repel each other and form fewer entanglement points. Therefore, UHMWPE acts as the stress concentration point when the blend is subjected to stress, and its contact molecules with PP are easily disentangled, which results in matrix peeling and reduces the mechanical properties of the blend. With the addition of elastomer OBC, the compatibility between PP and UHMWPE is improved. Its hard segment can form winding structure with UHMWPE, while the soft segment can form winding structure with PP. As a bridge, PP and UHMWPE are tightly bound together, which significantly increases the chain winding density of blends and makes blends more flexible. ${ }^{21}$ The entanglement of molecular chains consumes a lot of energy and improves the mechanical properties of the blends remarkably.

Table 3 Surface energies of PP, OBC, and UHMWPE

\begin{tabular}{llllll}
\hline Sample & $\begin{array}{l}\text { Contact angle } \\
\theta \mathrm{H}_{2} \mathrm{O}\left(^{\circ}\right)\end{array}$ & $\begin{array}{l}\text { Contact angle } \\
\theta \mathrm{CH}_{2} \mathrm{I}_{2}\left(^{\circ}\right)\end{array}$ & $\begin{array}{l}\text { Surface energy } \\
\gamma\left(\mathrm{mN} \mathrm{m}^{-1}\right)\end{array}$ & $\begin{array}{l}\text { Dispersion component } \\
\gamma^{\mathrm{d}}\left(\mathrm{mN} \mathrm{m}^{-1}\right)\end{array}$ \\
\hline PP & 151.1 & 148.9 & 34.7 & 33.4 & $\begin{array}{l}\text { Polar component } \\
\gamma^{\mathrm{p}}\left(\mathrm{mN} \mathrm{m}^{-1}\right)\end{array}$ \\
OBC & 144.5 & 145.8 & 36.9 & 34.4 & 2.3 \\
$\mathrm{UHMWPE}$ & 100.2 & 121.8 & 36.1 & 34.4 & 1.7 \\
$\mathrm{H}_{2} \mathrm{O}$ & - & - & 72.8 & 21.8 & 51 \\
$\mathrm{CH}_{2} \mathrm{I}_{2}$ & - & - & 50.8 & 48.5 & 2.3
\end{tabular}


Table 4 Interfacial tensions and adhesive energies among PP, OBC, and UHMWPE

\begin{tabular}{llr}
\hline Sample & Interfacial tension $\gamma_{12}\left(\mathrm{mN} \mathrm{m}^{-1}\right)$ & Adhesive energy $W_{12}\left(\mathrm{mN} \mathrm{m}^{-1}\right)$ \\
\hline PP/OBC & 0.4 & 71.4 \\
OBC/UHMWPE & 0.15 & 73.0 \\
PP/UHMWPE & 0.07 & 71.0
\end{tabular}

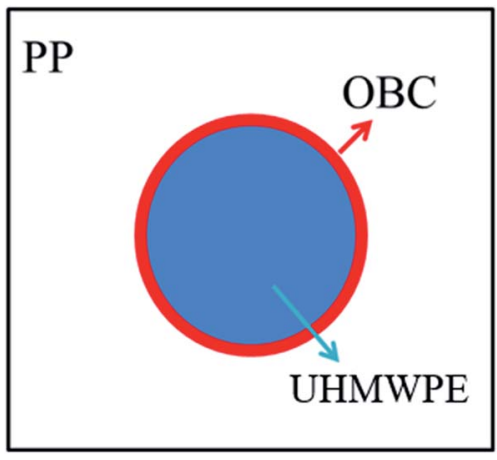

Fig. 5 The core-shell structure of the blends.

\subsection{Section morphology of the blends}

The cross sections of blends with different OBC and UHMWPE contents were scanned by SEM to analyze the dispersed morphology of PP, OBC and UHMWPE. As shown in Fig. 3, it can be seen that the PP/UHMWPE blends formed the cross section morphology with UHMWPE as the dispersed phase and $\mathrm{PP}$ as the continuous phase. Due to the poor fluidity of UHMWPE, it can be seen that the dispersion of UHMWPE in PP was not uniform, and phase separation occurred between UHMWPE and PP. The cross section of PP/OBC/UHMWPE showed that the blend formed a coating structure with OBC as shell and UHMWPE as core. OBC was dispersed on the interface between PP and UHMWPE. At this time, UHMWPE was embedded in PP matrix, which indicated that OBC significantly improved the compatibility between PP and UHMWPE. When the OBC content was $3 \mathrm{wt} \%$, we can see that some UHMWPE particles have been encapsulated by OBC. When the
OBC content reached $6 \mathrm{wt} \%$, UHMWPE was almost completely encapsulated by OBC. On the other hand, when the content of UHMWPE was less than $1 \mathrm{wt} \%$, all the particles were surrounded by OBC. When the content of UHMWPE exceeded $1 \mathrm{wt} \%$, some UHMWPE was directly dispersed in PP matrix (Fig. 3). When the content of UHMWPE reached $2 \mathrm{wt} \%$, significant UHMWPE aggregates were formed. The SEM with higher magnification was shown in the following figures (Fig. 4) of the ESI. $\dagger$

\subsection{Formation mechanism of section morphology}

The contact angles of PP, OBC and UHMWPE were measured in order to analyze the dispersed forms of PP, OBC and UHMWPE in blends. As shown in Table 3 the surface energy of PP, OBC and UHMWPE was calculated by using formulas (2), (3) and (4).

In order to analyze the interfacial interaction between PP, OBC and UHMWPE, the interfacial tension and adhesion work of the three materials were calculated by using formulas (5) and (6), which are listed in Table 4. It can be seen that the adhesion work of UHMWPE and PP was obviously greater than that of OBC. In addition, UHMWPE has more chain winding structure, and its fluidity is lower. When blended with $\mathrm{PP}$ and $\mathrm{OBC}$, UHMWPE tends to bind to OBC with the same viscosity. Therefore, the blends will form OBC-coated UHMWPE structure, as shown in Fig. 5.

\subsection{Thermal properties of the blends}

The thermal properties of $\mathrm{PP} / \mathrm{OBC} / \mathrm{UHMWPE}$ blends were shown in Fig. 6 and 7, Table S.3. $\dagger$ The crystallinity of PP/OBC/ UHMWPE blends increased first and then decreased with the increase of UHMWPE content. When the content of UHMWPE
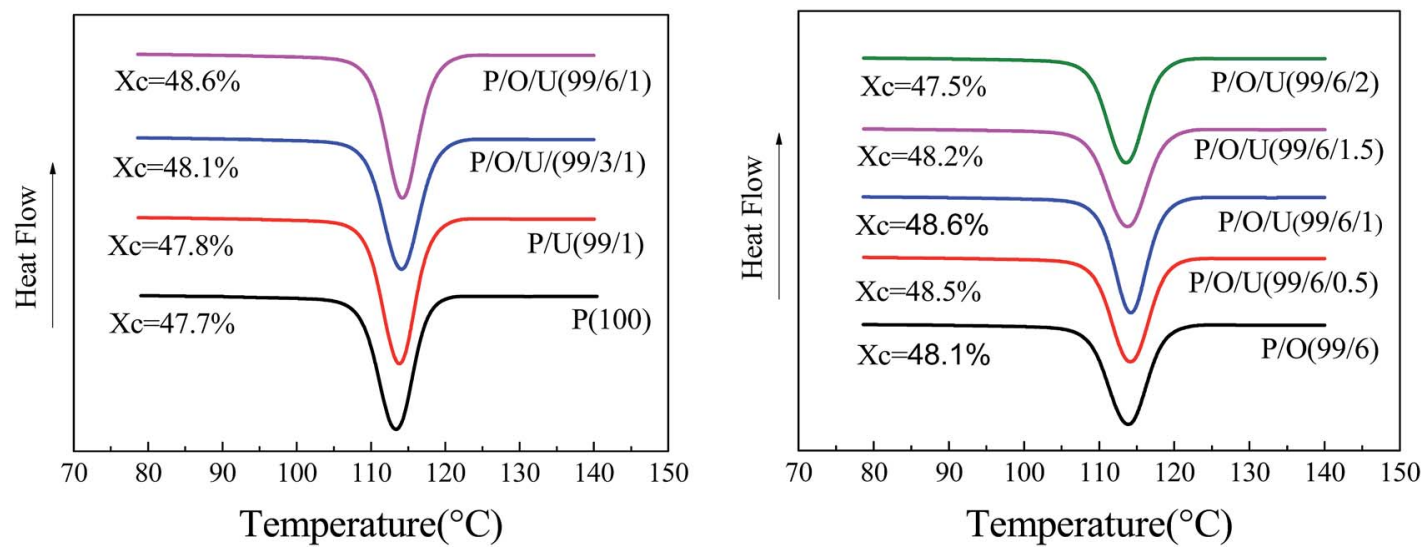

Fig. 6 Crystallization curves of PP/OBC/UHMWPE blends with different OBC contents. 

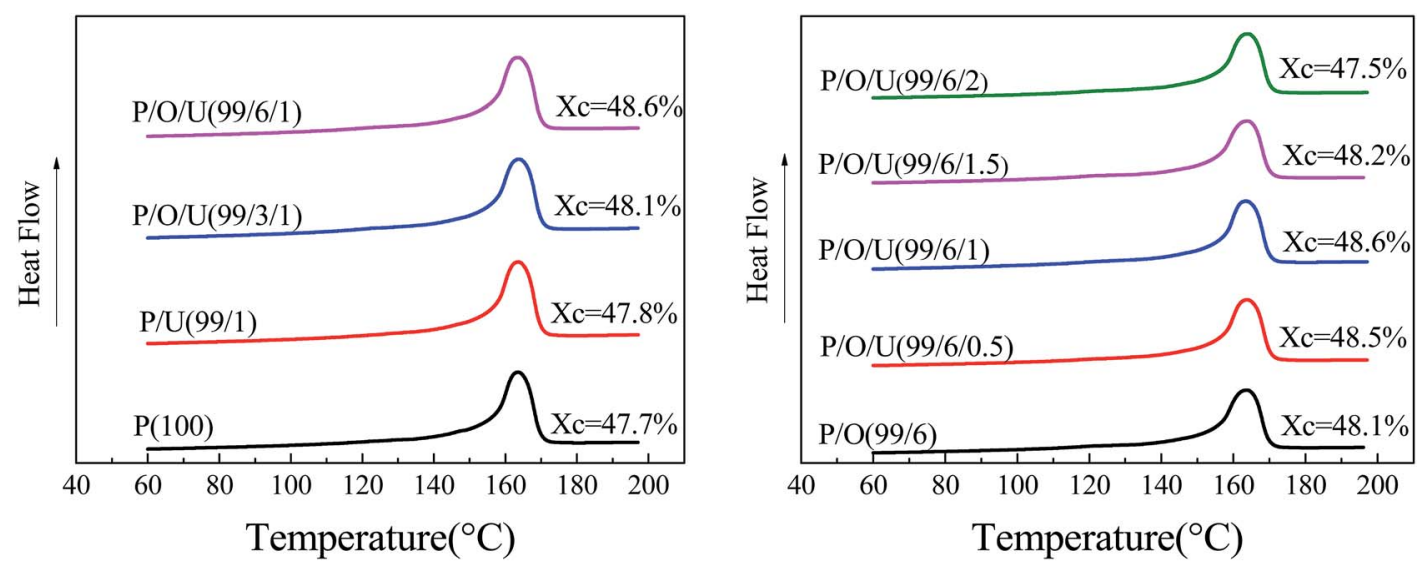

Fig. 7 Melting curves of PP/OBC/UHMWPE blends with different UHMWPE contents.

was $1 \mathrm{wt} \%$, the crystallinity of $\mathrm{PP} / \mathrm{OBC}$ blends increased from $48.1 \%$ to $48.6 \%$, and when the content of UHMWPE exceeded $1 \mathrm{wt} \%$, the crystallinity of the blends began to decrease, which indicated that the addition of UHMWPE had a competitive effect on the crystallization behavior of the blends. On the one hand, the existence of UHMWPE as a heterogeneous nucleus was conducive to improving the crystallinity of the polymers. On the other hand, the interaction between UHMWPE and polymer chains hindered the movement of macromolecular chains and the orderly arrangement of molecular chains, thus reducing the crystallinity of polymers. When the content of UHMWPE was less than $1 \mathrm{wt} \%$, its dispersion in blends was more uniform, and heterogeneous nucleation of UHMWPE played a leading role. Therefore, the crystallinity of blends showed an upward trend. When the content of UHMWPE was over $1 \mathrm{wt} \%$, it formed obvious aggregates, hindered the movement of molecular chains and destroyed the orderly arrangement of molecular chains. The crystallinity of the blends tended to decrease.

In addition, it can be seen that the crystallization temperature and crystallinity of the blends increased with the increase of OBC content. This is because as a compatibilizer, OBC improved the interface compatibility between $\mathrm{PP}$ and UHMWPE, which was more likely to induce heterogeneous nucleation at the interface.

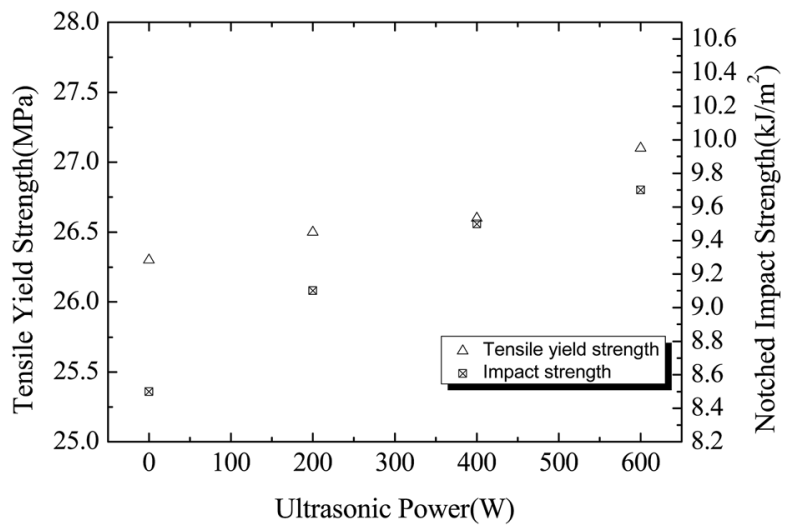

Fig. 9 Mechanical properties of PP/OBC/UHMWPE blends at different ultrasonic power levels.

\subsection{Rheological properties of PP/OBC/UHMWPE blends}

As shown in Fig. 8 (left), the blend viscosity-shear frequency curve shows that in low frequency, the viscosity of PP/UHMWPE blends was obviously lower than that of pure PP. Because UHMWPE had higher molecular weight than PP and they had poor compatibility. The polymer chains of UHMWPE and PP

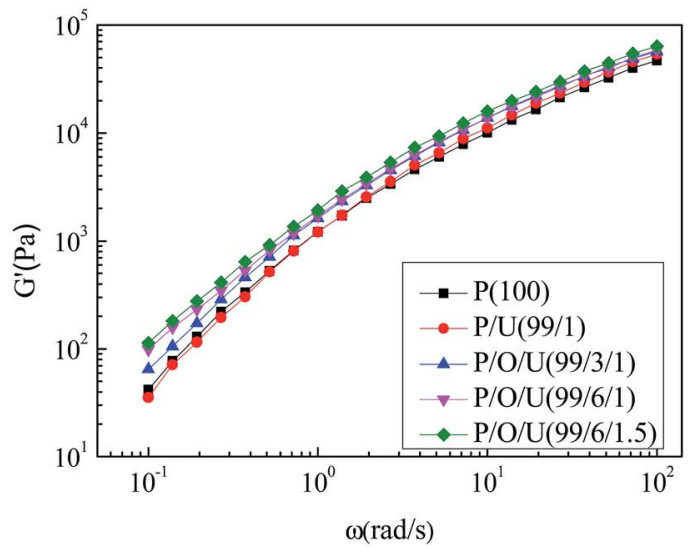

Fig. 8 Viscosity-shear frequency (left) and storage modulus-shear frequency (right) curves of PP/OBC/UHMWPE blends. 

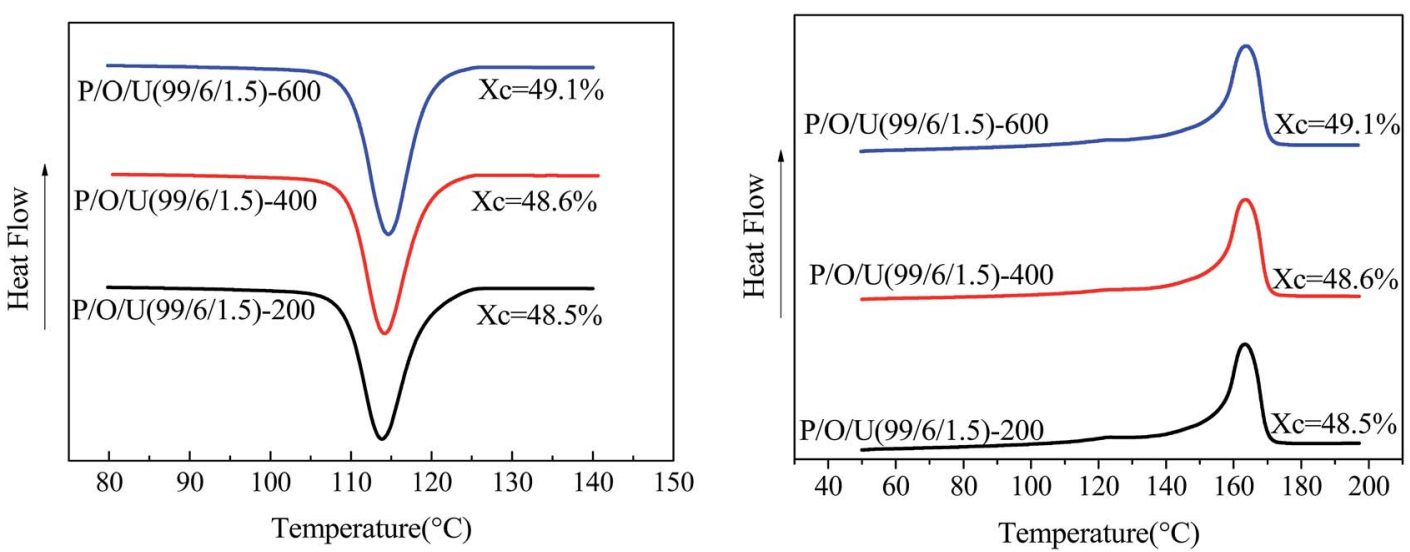

Fig. 10 Crystallization (left) and melting (right) curves of PP/OBC/HDPE blends at different ultrasonic power levels.

were mutually exclusive. A small amount of UHMWPE dispersed in PP acts as lubricant. (Mutual exclusion decreased friction between chains) reduced the flow resistance of PP. With the addition of elastomer OBC, the viscosities of blends increased obviously. On one hand, OBC improved the compatibility of PP and UHMWPE, and increased the degree of molecular chain entanglement between them; on the other hand, OBC had higher viscosities, which would lead to the increase of the viscosities of blends. As shown in Fig. 8 (right), the energy storage modulus-shear frequency curve of blends proved that in low frequency region the addition of elastomer OBC improved the energy storage modulus of blends. The addition of OBC marked PP and UHMWPE molecular chains entangled tightly, which made the relaxation time of blends longer and the storage modulus higher in low frequency region. In general, OBC and UHMWPE had little effect on the viscosity and storage modulus of the blends, and the blends still had good processing properties.

\subsection{Melt flow rate of PP/OBC/UHMWPE blends}

The MFR of the blends was tested in order to investigate the processing fluidity of the blends. The addition of UHMWPE ( $1 \mathrm{wt} \%$ ) in PP increased the MFR of the blends and improved the fluidity. The addition of OBC decreased the MFR of the blends slightly. MFR of the blends ranged from 2.8 to $3.8 \mathrm{~g} /$ $10 \mathrm{~min}$ in general, proved a good fluidity.

This also gave us a revelation that although UHMWPE was difficult to process and apply, it could improve the mechanical properties of materials while have little effect on the processing properties of polymers by adding a small amount of UHMWPE. And its mechanical properties were tested and section morphology was recorded.

\subsection{Effect of ultrasonic irradiation on properties of $\mathrm{PP} / \mathrm{OBC} /$ UHMWPE blends}

Compared with the blends without ultrasonic irradiation, UHMWPE was easy to form aggregates because of its poor fluidity. For example, phase separation between UHMWPE and PP exists in a blend PP/OBC/UHMWPE with $1.5 \mathrm{wt} \%$ UHMWPE. Therefore,
UHMWPE was treated by ultrasound irradiation in order to improve the dispersion of UHMWPE in blends, and its mechanical properties were tested and section morphology was recorded and shown in Fig. 9. The molecular weight, molecular distribution and mechanical properties of PP were not changed under the ultrasound as shown in Tables S.1 and S.2. $\dagger$ It can be seen that with the increase of ultrasonic power, the tensile yield strength and impact strength of the blends increase gradually. Compared with the blends without ultrasonic irradiation, the tensile yield strength and impact strength of the blends obtained by ultrasonic $600 \mathrm{~W}$ increased by $0.8 \mathrm{MPa}$ and $1.2 \mathrm{~kJ} \mathrm{~m}^{-2}$ respectively.

SEM analysis showed that the phase separation between PP and UHMWPE disappeared after ultrasonic treatment (Fig. 3). UHMWPE had smaller particle size and were almost embedded in PP matrix. This was because ultrasound improved the compatibility between PP and UHMWPE and made UHMWPE dispersed uniformly in PP matrix, and thus decreased the size of PP/OBC/UHMWPE core-shell structures, ${ }^{17}$ which played a role in strengthening and toughening PP.

The crystallization and melting curves of the blends treated with different ultrasonic power are shown in Fig. 10 and Table S.4. $\dagger$ It can be seen that the crystallization peak of the blends shifts to the right with the increase of ultrasonic power. Under $600 \mathrm{~W}$ ultrasonic power, the crystallization temperature of the blends increases by $1.2 \mathrm{~K}$. This was because UHMWPE aggregates were broken by ultrasound, which made UHMWPE uniformly dispersed in PP matrix, which played a role of heterogeneous nucleation of PP and improved the crystallization temperature of blends.

\section{Conclusions}

Blends of PP, UHMWPE, and OBC were prepared using a twin-screw extruder under the application of ultrasonic irradiation. The addition of UHMWPE in PP did not improve the mechanical properties due to the poor compatibility between UHMWPE and PP. The addition of elastomer OBC improved the compatibility of PP with UHMWPE and nearly doubled the notched impact strength. In addition, the SEM images of blend sections showed that PP/ UHMWPE blends exhibited phase separation, but OBC almost 
completely dispersed on the phase interface between PP and UHMWPE, which proves its effect as an efficient compatibility modulator. Besides, the addition of OBC and UHMWPE in PP matrix played a role of heterogeneous nucleation which causes an increase of crystallization temperature of the blends. When the content of UHMWPE was over $1 \mathrm{wt} \%$, the formation of a UHMWPE agglomeration structure hindered the crystallization of the blends and made the crystallization temperature decrease. UHMWPE in $\mathrm{PP} / \mathrm{OBC} / \mathrm{UHMWPE}$ blends dispersed more evenly under the action of ultrasound, and its mechanical properties were further improved. UHMWPE played a better role in heterogeneous nucleation and increased the crystallization temperature of the blends.

\section{Conflicts of interest}

There are no conflicts to declare.

\section{Acknowledgements}

This work is financially supported by the National Natural Science Foundation of China (No. 51573048) and Natural Science Foundation of Shanghai (No. 16R1407300).

\section{References}

1 R. A. Shanks, J. Li and L. Yu, Polypropylene-polyethylene blend morphology controlled by time-temperaturemiscibility, Polymer, 2000, 41(6), 2133-2139.

$2 \mathrm{~V}$. Flaris, A. Wasiak and W. Wenig, The effect of compatibilizers on the morphology of isotactic polypropylene/linear low-density polyethylene blends, $J$. Mater. Sci., 1993, 28(6), 1685-1688.

3 P. Schmidt, J. Baldrian, J. Scudla, J. Dybal, M. Raab and K. J. Eichhorn, Structural transformation of polyethylene phase in oriented polyethylene/polypropylene blends: a hierarchical structure approach, Polymer, 2001, 42(12), 5321-5326.

4 H. P. Blom, A. Rudin and J. W. Teh, I-PP/HDPE blends. 3:characterization and compatibilization at lower i-PP contents, J. Appl. Polym. Sci., 1996, 61(6), 959-968.

5 M. M. Dumoulin, P. J. Carreau and L. A. Utracki, Rheological properties of linear low-density polyethylene polypropylene blends. 2:solid-state behavior, Polym. Eng. Sci., 1987, 27(21), 1627-1633.

6 J. W. Teh, A. Rudin and J. C. Keung, A review of polyethylenepolypropylene blends and their compatibilization, $A d v$. Polym. Technol., 1994, 13(1), 1-23.

7 D. W. Bartlett, J. W. Barlow and D. R. Paul, Mechanical properties of blends containing HDPE and PP, J. Appl. Polym. Sci., 1982, 27(7), 2351-2360.

8 A. I. Yeh, S. J. Hwang and J. J. Guo, Effects of screw speed and feed rate on residence time distribution and axial mixing of wheat flour in a twin-screw extruder, J. Food Eng., 1992, 17(1), 1-13.

9 S. Lapshin and A. I. Isayev, Continuous process for melt intercalation of PP-clay nanocomposites with aid of power ultrasound, J. Vinyl Addit. Technol., 2006, 12(2), 78-82.
$10 \mathrm{~W}$. Feng and A. I. Isayev, In situ compatibilization of $\mathrm{PP} /$ EPDM blends during ultrasound aided extrusion, Polymer, 2004, 45(4), 1207-1216.

11 A. I. Isayev, R. Kumar and T. M. Lewis, Ultrasound assisted twin screw extrusion of polymer-nano composites containing carbon nanotubes, Polymer, 2009, 50(1), 250-260.

12 Y. Chen and H. Li, Phase morphology evolution and compatibility improvement of PP/EPDM by ultrasound irradiation, Polymer, 2005, 46(18), 7707-7714.

13 A. L. N. Da Silva, M. I. B. Tavares, D. P. Politano, et al., Polymer blends based on polyolefin elastomer and polypropylene, J. Appl. Polym. Sci., 1997, 66(10), 2005-2014.

14 J. Yang, Y. Zhang and Y. Zhang, Brittle-ductile transition of $\mathrm{PP} / \mathrm{POE}$ blends in both impact and high speed tensile tests, Polymer, 2003, 44(17), 5047-5052.

15 A. Batistini, New polyolefin plastomers and elastomers made with insite ${ }^{\mathrm{TM}}$ technology: Structure-property relationship and benefits in flexible thermoplastic applications, Macromol. Symp., 1995, 100(1), 137-142.

16 D. J. Arriola, E. M. Carnahan, P. D. Hustad, et al., Catalytic production of olefin block copolymers via chain shuttling polymerization, Science, 2006, 312(5774), 714-719.

17 H. P. Wang, S. P. Chum, A. Hiltner, et al., Comparing elastomeric behavior of block and random ethylene-octene copolymers, J. Appl. Polym. Sci., 2009, 113(5), 3236-3244.

18 S. G. Pardo, C. Bernal, M. J. Abad, et al., Fracture and thermal behaviour of biomass ash polypropylene composites, $J$. Thermoplast. Compos. Mater., 2014, 27(4), 481-497.

19 G. Liu, X. Zhang, X. Li, et al., Correlation of miscibility and mechanical properties of polypropylene/olefin block copolymers: Effect of chain composition, J. Appl. Polym. Sci., 2012, 125(1), 666-675.

20 Z. Li, Y. J. Shi, C. X. Sun, et al., In situ micro and nano fibrillar reinforced elastomer composites based on polypropylene (PP)/olefinic block copolymer (OBC), Compos. Sci. Technol., 2015, 115, 34-42.

21 X. He, J. Shi, L. Wu, et al., Study on synergistic toughening of polypropylene with high-density polyethylene and elastomer-olefin block copolymers under ultrasonic application, Compos. Sci. Technol., 2018, 161, 115-123.

22 G. D. Liu, Y. Z. Chen and H. L. Li, Study on processing of ultrahigh molecular weight polyethylene/polypropylene blends: Capillary flow properties and microstructure, $J$. Appl. Polym. Sci., 2004, 94(3), 977-985.

23 E. N. Brown, R. B. Willms, G. T. Gray, et al., Influence of Molecular Conformation on the Constitutive Response of Polyethylene: A Comparison of HDPE, UHMWPE, and PEX, Exp. Mech., 2007, 47(3), 381-393.

$24 \mathrm{~J}$. H. Chen, B. X. Yao, W. B. Su, et al., Isothermal crystallization behavior of isotactic polypropylene blended with small loading of polyhedral oligomeric silsesquioxane, Polymer, 2007, 48(6), 1756-1769.

25 A. Krumme, A. Lehtinen and A. Viikna, Crystallisation behaviour of high density polyethylene blends with bimodal molar mass distribution: 2. Non-isothermal crystallisation, Eur. Polym. J., 2004, 40(2), 371-378. 